\title{
Fabrication of SS316L to Ni80Cr20 graded structures by 3D plasma metal deposition
}

\author{
K. Hoefer ${ }^{1} \cdot$ J. Rodriguez ${ }^{2} \cdot$ A. Haelsig ${ }^{1} \cdot$ K.-G. Abstoss ${ }^{1} \cdot$ P. Mayr ${ }^{1}$
}

Received: 7 October 2019 / Accepted: 17 February 2020 / Published online: 6 March 2020

(C) The Author(s) 2020

\begin{abstract}
Powder metallurgy and thermal spraying has been used traditionally to manufacture functionally graded materials (FGMs). However, only simple geometries can be made with these processes and the compositional gradients cannot be tailored. These disadvantages can be overcome by employing additive manufacturing (AM). 3D plasma metal deposition (3DPMD) is a new technique that combines the advantages of plasma powder and additive processes. This process allows the production of structures with mixtures of different materials and powder fraction targeting changes in local properties and microstructures. For example, up to four powders, which can be different in terms of chemistry and powder fraction, can be mixed within one layer to adapt the local properties of the structure. The feasibility of functionally graded structures of stainless steel $316 \mathrm{~L}$ (SS316L) and Ni80-20 alloy was studied. Two configurations, transition between the steel and the Ni-based alloy, were tested. The first one is hard transition, SS316L on the bottom and Ni80-20 on the top. The second one, a smooth transition between both materials was created with $50 \%$ of steel and $50 \%$ of Ni-based alloy. Optical microscopy and scanning electron microscopy were used to characterize the microstructures. The manufactured part showed good appearance, without any external defects and acceptable geometric accuracy. The layer thickness was around $z=1 \mathrm{~mm}$ for both structures. Regarding the microstructural characterization, both materials displayed a dendritic structure. In the SS316L, the microstructure was composed by an austenitic matrix with $\delta$ ferrite located in the grain boundaries. The microstructure of the Ni80-20 was characterized as an austenitic matrix, with some $\mathrm{M}_{7} \mathrm{C}_{3}$ and $\mathrm{M}_{23} \mathrm{C}_{6}$ precipitates. In addition, the Laves phase was also observed.
\end{abstract}

Keywords Additive manufacturing $\cdot$ Austenitic stainless steel $\cdot$ Ni-based alloy $\cdot$ 3DPMD $\cdot$ Functionally graded

This article is part of the collection Additive Manufacturing - Processes, Simulation and Inspection Recommended for publication by Commission I - Additive Manufacturing, Surfacing, and Thermal Cutting

K. Hoefer

kevin.hoefer@mb.tu-chemnitz.de

J. Rodriguez

johnnatan.rodriguez@eia.edu.co

A. Haelsig

andre.haelsig@tu-chemnitz.de

K.-G. Abstoss

kevin.abstoss@mb.tu-chemnitz.de

P. Mayr

peter.mayr@mb.tu-chemnitz.de

1 Chemnitz University of Technology, Reichenhainer Straße 70, 09126 Chemnitz, Germany

2 Department of Mechanical Engineering, EIA University, Envigado, Antioquia, Colombia

\section{Introduction}

The main advantages of multi-material additive manufacturing (MMAM) are the possibility of local variation of the part properties [1] or materials composition [2] depending on the real loads. MMAM is defined as the layer-by-layer production of components made of formless material, as opposed to subtractive or formative manufacturing methodologies, with locally modified properties. The local adaptation of the component porosity, following the example of human bone, is an example of this [3-5]. The advantages of continuous material change are higher tolerable loads [6], lower thermal stresses [7-12], and a reduced tendency to cracks [13]. In this work, multi-material components with a continuous and abrupt transition from steel to nickel-based alloy are produced.

The advanced 3D plasma metal deposition process is used for this purpose. 3D plasma metal deposition process (3DPMD) is a development of the classic plasma transfer arc (PTA) process with adaptations to the requirements of 
Table 1 Chemical composition of the powders used (wt $\%$ )

\begin{tabular}{llllllll}
\hline Alloy & $\mathrm{C}$ & $\mathrm{Si}$ & $\mathrm{Mn}$ & $\mathrm{Cr}$ & $\mathrm{Mo}$ & $\mathrm{Ni}$ & $\mathrm{Fe}$ \\
\hline SS316L & 0.03 & 0.7 & 0.5 & 16.5 & 2.1 & 13.0 & Bal. \\
Ni80-20 & - & 1.2 & - & 22.0 & - & Bal. & 0.6 \\
\hline
\end{tabular}

additive manufacturing. Previous research has used the micro PTA to produce graded components from Ni-based alloy with $\mathrm{Al}_{2} \mathrm{O}_{3}$ ceramics [14]. However, the lower build-up rates and the higher demands on powder quality are the disadvantages compared with $3 \mathrm{DPMD}$. This is characterized by a build-up rate of up to $10 \mathrm{~kg} / \mathrm{h}$, low demands on powder quality, and the ability to process up to four powders simultaneously. Further information on the process and the materials to be processed can be found in earlier publications [2,15-17]. Previous work on the production of graded steel and nickel-based components has primarily used beam-based direct energy deposition processes such as laser metal deposition [18], laser cladding [19], or laser rapid forming [20]. Applications of laserbased powder bed processes are also well known [1].

In this study, an austenitic stainless steel $316 \mathrm{~L}$ and a heat-resistance Ni-based alloy Ni80-20 are employed [20]. These alloys are used in different industries, such as petrochemical, shipbuilding, and nuclear. Multi-material structures of these alloys were manufactured using 3DPMD. Two configurations were studied; the first one is a smooth transition between both materials with a transition region of $50 \% \mathrm{SS} 316 \mathrm{~L} / 50 \% \mathrm{Ni} 80-20$ and the second one, a hard transition (discrete transition between the materials). The effects of the process parameters on the geometry and the microstructure were investigated.

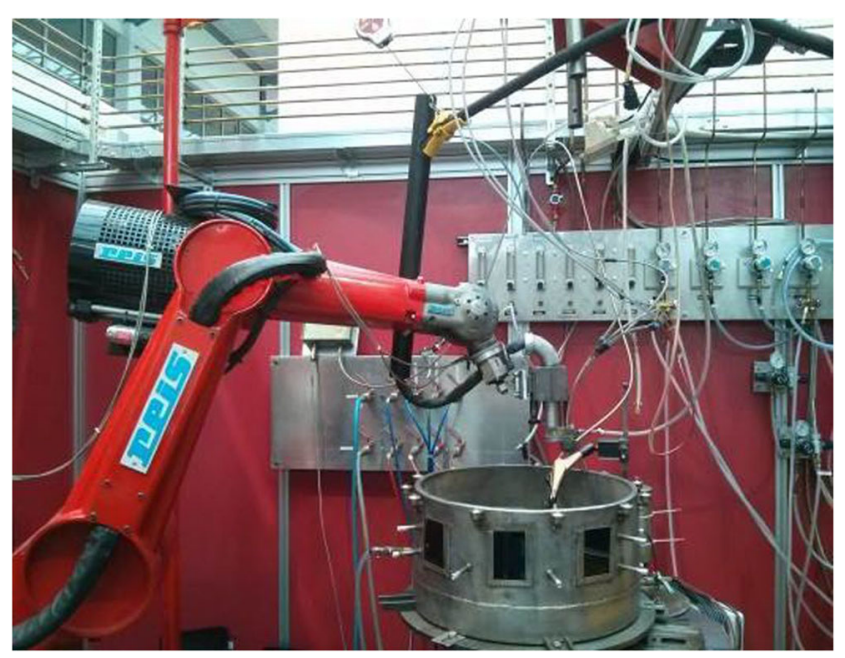

Fig. 1 Experimental setup for 3DPM7D. Adapted from [2]

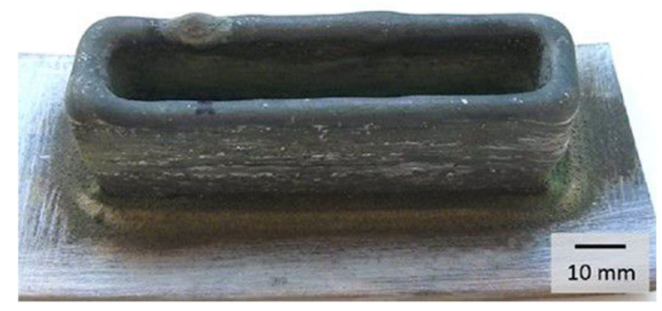

Fig. 2 Structure manufactured by 3DPMD

\section{Materials and experimental procedure}

Functionally graded structures of stainless steel $316 \mathrm{~L}$ and Ni80-20 alloy were fabricated using 3DPMD. Table 1 shows the chemical composition of the powder used. Both materials have a FCC structure with similar lattice parameters. For the base platform (BP), a $t=10 \mathrm{~mm}$ thick plate of SS316L was employed. Two configurations of fabrication were used. The first one (hard transition, HT), SS316L on the bottom and Ni80-20 on the top. Fifteen layers of each material were applied for the HT configuration. The second one (smooth transition, ST), a transition region (mix zone) between both materials was made with $50 \%$ of steel and $50 \%$ of Ni-based alloy. Thirty layers in total were applied for this configuration, ten for each material. The structures have a length of $l=120 \mathrm{~mm}$, width of $w=30 \mathrm{~mm}$, and height of $h=30 \mathrm{~mm}$. The build-up process was continuous without interruption of the welding process between the layers and with a constant layer thickness of $1 \mathrm{~mm}$

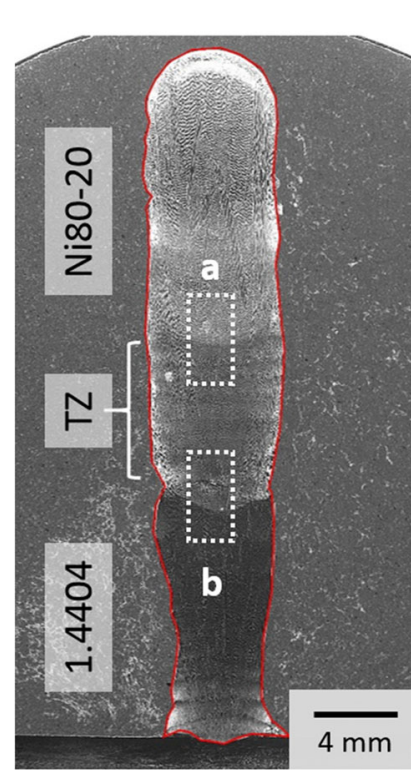

a)

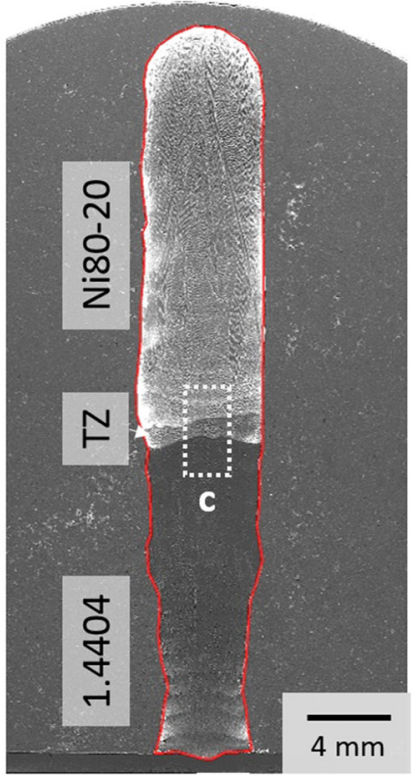

b)
Fig. 3 Macro view of the functionally structures built. a Smooth transition. b Hard transition 


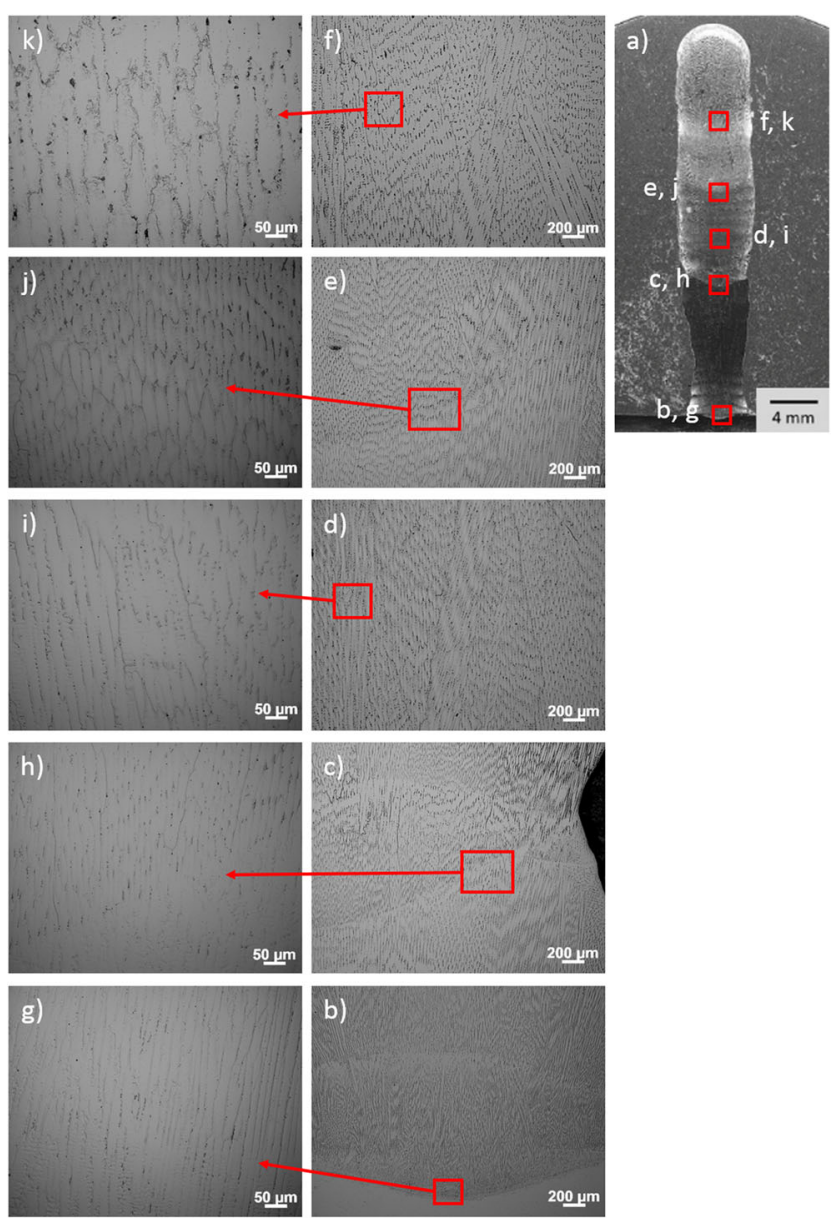

Fig. 4 Microstructure characterization of the ST sample. a) Macro of the 3D structure. b), g) Interface with the base platform and stainless steel (316L). c), h); Interface between SS316L and transition zone. d), i) Transition zone. e), j) Interface between the transition zone and Ni8020. f), k) Ni-based alloy (Ni80-20). b)-k) OM images

A welding torch PlasmaStar MV230 $\left(I_{\max }=230\right.$ A) equipped with two separate powder feeds and a power source PlasmaStar $500\left(I_{\max }=500 \mathrm{~A}\right)$ were used to build the structures. Powders with a particle size between 50 and $150 \mu \mathrm{m}$ of both materials were fed with a meander disk feeder. Highpurity argon was employed as shielding and plasma gas. A six axis-articulated arm robot REIS RV20-16 was used as a manipulation system (Fig. 1).

$v_{\mathrm{s}}=10 \mathrm{~mm} \mathrm{~s}^{-1}$ and $U_{\mathrm{s}}=23 \mathrm{~V}$ were used as a constant welding speed and voltage, respectively, during the deposition of the layers. The welding current was $I_{\mathrm{S}}=120 \mathrm{~A}$ for the $\mathrm{SS} 316 \mathrm{~L}, I_{\mathrm{S}}=105 \mathrm{~A}$ for the Ni80-20, and $I_{\mathrm{S}}=110 \mathrm{~A}$ for the mixture powder ( $50 \%$ of steel and $50 \%$ of Ni-based alloy).

For the metallographic examinations, cross-section specimens from the fabricated structures were obtained. Standard metallographic preparation was used. A total of $10 \%$ oxalic acid was used at $2 \mathrm{~V}$ for $30 \mathrm{~s}$ to reveal the microstructures of the asbuild deposits. The microstructure was observed using optical microscopy (OM) and scanning electron microscopy (SEM).

\section{Results and discussion}

The as-build structures presented good surface appearance without external cracks, voids, and partially molten powder particles. Due to the AM typical post-processing, this is negligible. Furthermore, good bonding with the base material was observed. The ST structure fabricated by 3DPMD is shown in Fig. 2 . Figure 3 depicts the macro view of the two structures. No internal irregularities were observed. As mentioned, the SS316L is located on the bottom and the Ni-based alloy on the top. The ST sample shows the continuous material transition with the transition zone (TZ) in the center. A wall thickness of $t=6.7 \mathrm{~mm}$ and a component height of $h=30.4 \mathrm{~mm}$ were measured. Concerning the number of layers of 30, a layer thickness of $z=1.01 \mathrm{~mm}$ was obtained. The evaluation of HT sample shows the abrupt material transition (see Fig. 3). Thus, the transition occurs in a narrow zone, one layer, compared with 10 layers of the ST structure. This was caused by the process typical dilution of the lower layer through the upper layer formation and cannot be avoided. Compared with the continuous material transition, the wall thickness is reduced by $\Delta t=16 \%$ to $t=5.6 \mathrm{~mm}$, and the component height is increased by $\Delta h=6.5 \%$ to $h=32.5 \mathrm{~mm}$. The layer thickness of $z=1.08 \mathrm{~mm}$ deviates only slightly.

The variable proportion of the nickel-based alloy in the total component can explain the variation of the component geometry. The lower thermal conductivity of the nickel-based
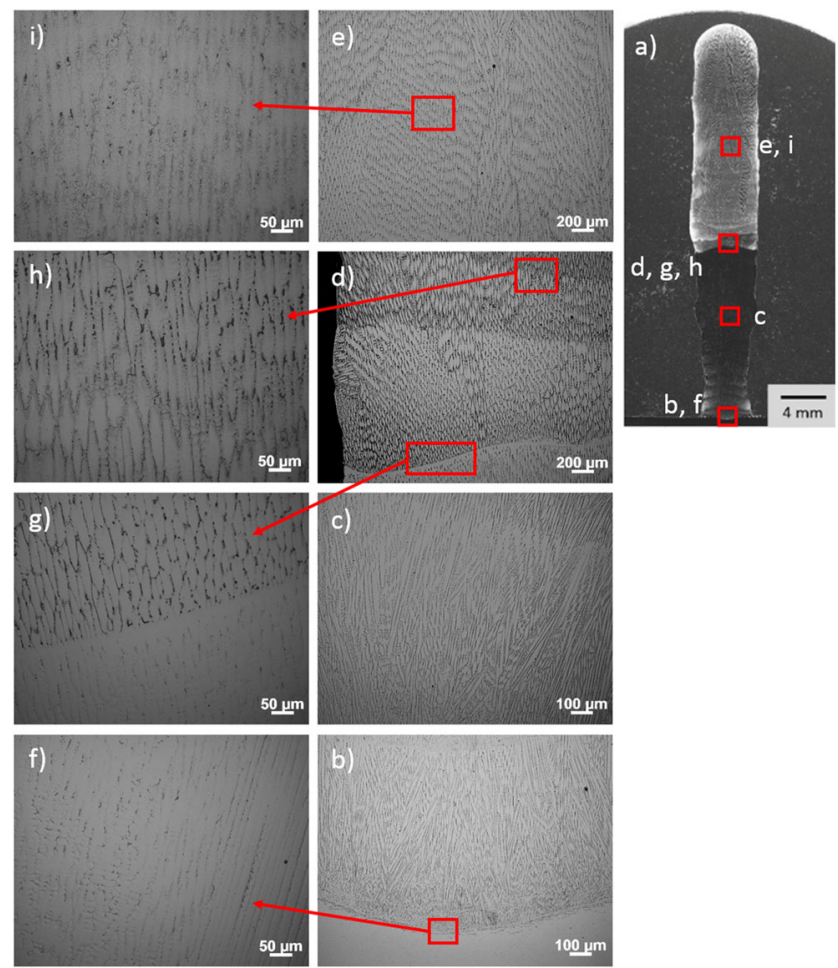

Fig. 5 Microstructure characterization of the HT sample. a) Macro of the 3D structure. b), f) Interface with the base platform. c) Stainless steel (316L), d), g), h) Interface between SS316L and Ni80-20. e), i) Nibased alloy (Ni80-20). b)-i) OM images 


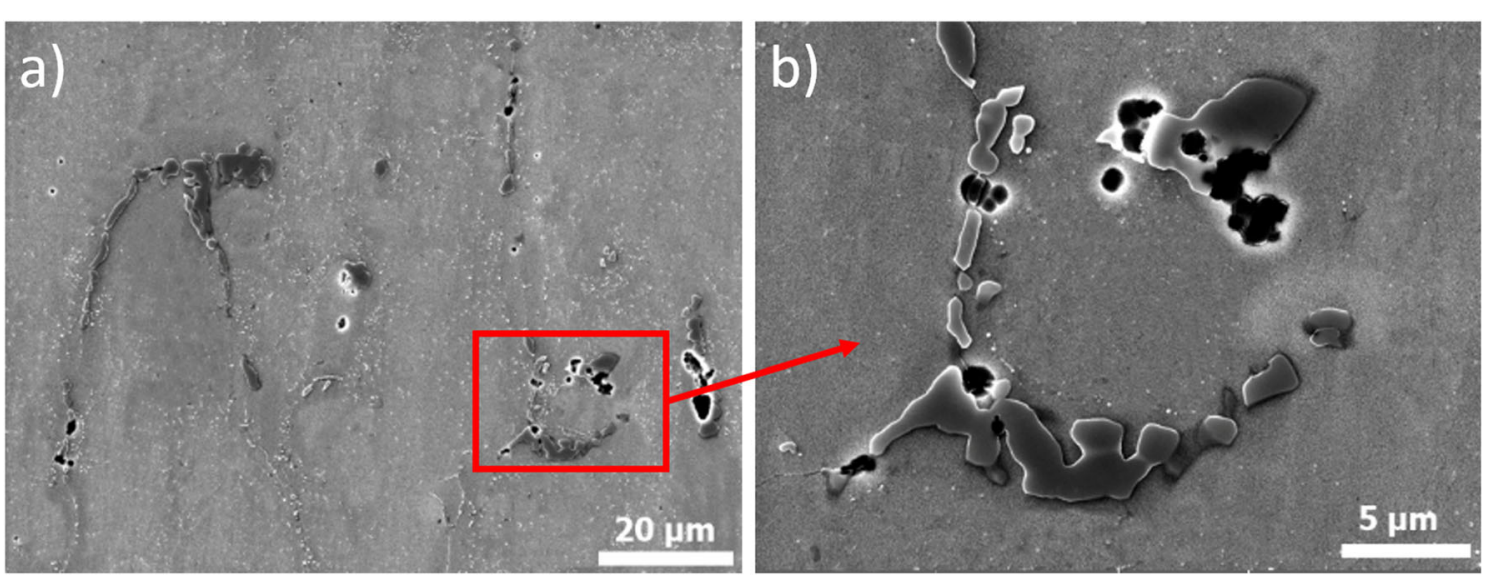

Fig. 6 Microstructure details of the Ni80-20 of the HT sample. SEM images

alloy leads to heat accumulation and thus to larger melt pool geometries with effects on the geometry. The larger the proportion of the nickel-based alloy in the entire component, the greater the effect on the same.

The as-deposited microstructures of both 3D structures are shown in Fig. 4 and Fig. 5 for the ST and HT sample, respectively. Comparing both structures, no significant differences were observed in the microstructure. However, the major difference is the presence of a transition region with a chemical composition gradient in the ST sample (Fig. 4d), i)).
The microstructural characterization of the stainless steel (bottom part of the structures) showed the presence of austenite and $\delta$-ferrite, as depicted in Fig. 4b), g) and Fig. 5b), f). At the interface with base platform, the precipitation of $\delta$-ferrite was also observed. The $\gamma$ matrix and the $\delta$-ferrite exhibited a dendrite and vermicular morphology, respectively. At the top part of the samples (Ni80-20 region), the microstructure was recognized as austenite $(\gamma)$ matrix with some $\mathrm{M}_{7} \mathrm{C}_{3}$ precipitates and the Laves phase (Fig. 4f), k) and Fig. 5e), i)). Intergranular and intragranular second phases were observed
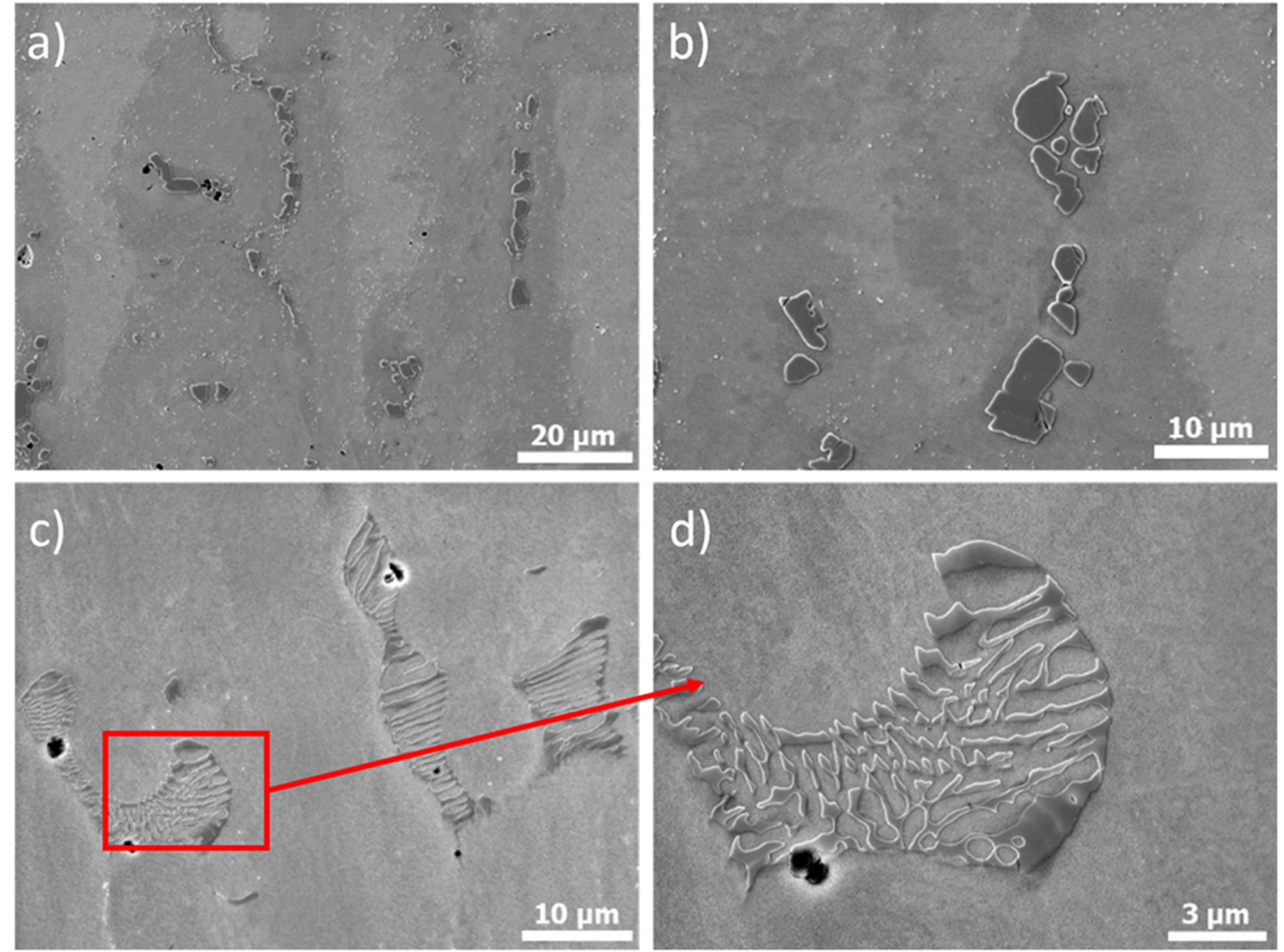

Fig. 7 Microstructure details of the ST sample. a), b) Ni80-20; c),d) mix zone. SEM images 
in the austenitic matrix. In addition, the $\gamma$ matrix presented a dendrite morphology. The main element for the $\mathrm{M}_{7} \mathrm{C}_{3}$ precipitate is the $\mathrm{Cr}$ and presented a roughly round morphology. On the other hand, based on the chemical composition of the Ni80-20 alloy, the intermetallic compound laves has an $\mathrm{A}_{2} \mathrm{~B}$ type structure and is classified as $(\mathrm{Ni}, \mathrm{Fe}, \mathrm{Cr})_{2}(\mathrm{Mo}, \mathrm{Si})$. A roughly continued morphology at the grain boundaries was noticed for the Laves phase. The microstructure of the Ni8020 for the HT sample is shown in Fig. 6.

At the mix zone of the ST structure, a dendrite morphology was observed corresponding to an austenite $(\gamma)$ matrix. Moreover, $\mathrm{M}_{7} \mathrm{C}_{3}$ precipitates and the Laves phase were identified in the microstructure. Changes in the chemical composition of the mix zone caused the variations in the morphology of the phases. Therefore, a change of the Laves morphology was observed with a $\gamma /$ laves eutectic type. Figure 7 depicts detailed view of the microstructure of the ST sample.

\section{Conclusions}

This work shows the feasibility of the 3D plasma metal deposition for fabrication of functionally graded structures of SS316L to Ni80-20. No external delamination or cracks were observed in the $3 \mathrm{D}$ structures. However, some pores were observed at the Ni-based.

The microstructural characterizations showed different phases on the 3D structures. The austenitic stainless steel showed an austenite $(\gamma)$ matrix with $\delta$-phase. The Ni80-20 exhibited austenite $(\gamma)$ matrix with some $\mathrm{M}_{7} \mathrm{C}_{3}$ precipitates and the Laves phase. The mix zone exhibited same microstructures, however changes in the morphology were observed.

In summary, 3DPMD was qualified as an effective process in multi-material additive manufacturing of transition structures from austenitic stainless steel to nickelbased alloys. Defect-free structures with a homogeneous transition with complete mixing in the transition zones were produced. The process offers great potential for other metal transitions.

Funding Information Open Access funding provided by Projekt DEAL.

Open Access This article is licensed under a Creative Commons Attribution 4.0 International License, which permits use, sharing, adaptation, distribution and reproduction in any medium or format, as long as you give appropriate credit to the original author(s) and the source, provide a link to the Creative Commons licence, and indicate if changes were made. The images or other third party material in this article are included in the article's Creative Commons licence, unless indicated otherwise in a credit line to the material. If material is not included in the article's Creative Commons licence and your intended use is not permitted by statutory regulation or exceeds the permitted use, you will need to obtain permission directly from the copyright holder. To view a copy of this licence, visit http://creativecommons.org/licenses/by/4.0/.

\section{References}

1. Popovich VA, Borisov EV, Popovich AA, Sufiiarov VS, Masaylo DV, Alzina L (2017) Functionally graded Inconel 718 processed by additive manufacturing: crystallographic texture, anisotropy of microstructure and mechanical properties. Adv Mater Res-Switz 114:441-449

2. Hoefer K, Nitsche A, Abstoß K-G, Ertugrul G, Haelsig A, Mayr P (2019) Multi-material additive manufacturing by 3D plasma metal deposition for graded structures of super duplex alloy 1.4410 and the austenitic corrosion resistant alloy 1.4404. JOM 71:1554-1559

3. Bandyopadhyay A, Krishna BV, Xue W, Bose S (2009) Application of laser engineered net shaping (LENS) to manufacture porous and functionally graded structures for load bearing implants. J Mater Sci Mater Med 20:29-34

4. Parthasarathy J, Starly B, Raman S (2011) A design for additive manufacture of functionally graded porous structures with tailored mechanical properties for biomedical applications. J Manuf Process 13:160-170

5. Murr LE, Gaytan SM, Martinez E, Medina F, Wicker RB (2012) Metal fabrication by additive manufacturing using laser and electron beam melting technologies. Int J Biomater 28:1-14

6. Sampath S, Herman H, Shimoda N, Saito T (1995) Thermal spray processing of FGMs. MRS Bull 20:27-31

7. Suresh S, Giannakopoulos AE, Alcalá J (1997) Sherical indentation of compositionally graded materials: theory and experiments. Acta Mater 45:1307-1321

8. Giannakopoulos AE, Suresh S (1997) Indentation of solids with gradients in elastic properties: part II axisymmetric indentors. Int J Solids Struct 34:2393-2428

9. Giannakopoulos AE, Suresh S, Finot M, Olsson M (1995) Elastoplastic analysis of thermal cycling: layered materials with compositional gradients. Acta Metall Mater 43:1335-1354

10. Williamson RL, Rabin RH, Drake JT (1993) Finite elements analysis of thermal residual stresses at graded ceramic-metal interfaces. J Appl Phys 74:1310-1320

11. Drake JT, Williamson RL, Rabin RH (1993) Finite elemete analysis of thermal residual stresses at graded ceramic-metal interfaces - part II microstructure. J Appl Phys 74:1321-1326

12. Erdogan F (1995) Fracture mechanics of functionally graded materials. Compos Eng 5:753-770

13. Zou H, Zhang H, Guilan W, Li J (2009) Rapid manufacturing of FGM components by using electromagnetic compressed plasma deposition. Electromagnetics research symposium (Moskau), pp.1953-1957

14. Hoefer K, Hälsig A, Mayr P (2018) Arc-based additive manufacturing of steel components -comparison of wire- and powder-based variants. Weld World 62:243-247

15. Hoefer K, Mayr P (2018) 3DPMD - additive manufacturing of titanium parts using 3D plasmametal deposition. Mater SciForum 941:2137-2141

16. Hoefer K, Teichgraeber C, Mayr P, Berger M (2017) Arc-based additive manufacturing - 3DPMD (Generative Fertigung mit Lichtbogenprozessen). In: Mayr P, Berger M (eds) Fümotec. Chemnitz University of Technology, Chemnitz, pp 1-14 (German)

17. Pulugurtha SR, Newkirk J, Liou F, Chou H (2010) Functionally graded materials by laser metal deposition (preprint). Proceedings of the 21st Annual International Solid Freeform Fabrication Symposium (2010, Austin, TX), University of Texas Press

18. Abboud JH, Rawlings RD, West DRF (1995) Functionally graded nickel-aluminide and iron-aluminide coatings produced via laser cladding. J Mater Sci 30:5931-5938

19. Xu X, Lin X, Chen J, He F, Huang W (2007) Laser rapid forming of Ti-Ni functionally graded alloy. Mater Sci Forum 561-565:227-230

20. Hüpf T, Cagran C, Kaschnitz E, Pottlacher G (2009) Thermophysical properties of Ni80Cr20. Thermochim Acta 494:40-44

Publisher's note Springer Nature remains neutral with regard to jurisdictional claims in published maps and institutional affiliations. 